\title{
Effects of Bacillus licheniformis on the growth performance and expression of lipid metabolism-related genes in broiler chickens challenged with Clostridium perfringens-induced necrotic enteritis
}

\author{
Mengjia Zhou ${ }^{1,2+}$, Dong Zeng ${ }^{1,2+}$, Xueqin $\mathrm{Ni}^{1,2^{*}}$, Teng Tu ${ }^{3}$, Zhongqiong Yin ${ }^{2}$, Kangcheng Pan ${ }^{1,2}$ and Bo Jing ${ }^{1,2}$
}

\begin{abstract}
Background: Necrotic enteritis (NE), caused by Clostridium perfringens, has cost the poultry industry \$2 billion in losses. This study aimed to investigate the effect of Bacillus licheniformis as dietary supplement on the growth, serum antioxidant status, and expression of lipid-metabolism genes of broiler chickens with C. perfringensinduced NE.

Methods: A total of 240 one-day-old broilers were randomly grouped into four: a negative control, an NE experimental model (PC), chickens fed a diet supplemented with $30 \%$ of fishmeal from day 14 onwards and challenged with coccidiosis vaccine (FC), and NE group supplied with feed containing $1.0 \times 10^{6} \mathrm{CFU} / \mathrm{g} \mathrm{B}$. licheniformis (BL).

Results: Body weight gain, feed conversion ratio, serum antioxidant status, and lipid-metabolism-gene expression were analyzed. In the PC group, FCR increased significantly whereas serum catalase and glutathione peroxidase activity decreased compared with NC group. Dietary B. licheniformis supplementation improved FCR and oxidative stress in experimental avian NE. Using Bacillus licheniformis as a direct-fed microbial (DFM) could also significantly upregulate catabolism-related genes, namely, peroxisome proliferator-activated receptor-a and carnitine palmitoyltransferase-1, in livers and changed the expression of lipid-anabolism genes.
\end{abstract}

Conclusion: These results suggested that dietary B. licheniformis supplementation can enhance growth and antioxidant ability, as well as change the expression of genes related to fatty-acid synthesis and oxidation in the livers of NE-infected broilers.

Keywords: Broiler chicken, Necrotic enteritis, Growth performance, Antioxidant, Lipid metabolism

\section{Background}

Necrotic enteritis (NE) is a type of enterotoxemia caused by Clostridium perfringens [1], it is a common disease affecting the poultry industry and the high contamination rates of poultry by C. perfringens can cause a threat to

\footnotetext{
* Correspondence: Xueqinni@foxmail.com

${ }^{\dagger}$ Equal contributors

${ }^{1}$ Animal Microecology Institute, College of Veterinary Medicine, Sichuan Agricultural University, Chengdu, Sichuan, China

${ }^{2}$ Key Laboratory of Animal Disease and Human Health of Sichuan Province, Chengdu, Sichuan, China

Full list of author information is available at the end of the article
}

public health through the food chain [2]. An NE outbreak in broiler chickens often results in high mortality rates and reduced growth performance [3, 4]. Various in-feed antibiotics have been used to prevent and control this disease [4-6]. However, the use of a large amount of antibiotics as growth promoters can cause antibioticresistant genes to spread extensively by promoting the selection of antibiotic-resistant bacteria in animals. In view of this concern, many countries have limited the use of non-therapeutic antibiotics in poultry feed; as a result, NE incidences have increased significantly over 
the past decade $[7,8]$. This disease costs the poultry industry $\$ 2$ billion annually in the purchase of drugs to treat NE and in the lost body weight gain (BWG) $[9,10]$. With the banning of in-feed antibiotics use, alternative methods of preventing NE outbreaks must be developed.

A potential approach to NE control is to supplement probiotics in the diets of broiler chickens to manipulate their gut ecosystems. Over the past few decades, Bacillus spp., such as B. licheniformis and B. subtilis, have been used in competitive exclusion experiments. B. subtilis competitively exclude $C$. perfringens from broiler chicks; in addition, these bacteria significantly improved body weight and feed efficiency [11-15]. B. licheniformis, which are "generally recognized as safe" bacteria, have long been extensively used in the poultry industry. This bacteria can serve as an alternative to antibiotics to enhance growth performance in poultry [16] and is a useful prebiotic for overcoming NE in a commercial-like condition $[17,18]$.

In broilers, the intermediary metabolism of lipids and energy usually occurs in the liver [19], as does the majority of the de novo fatty acid synthesis process [20,21]. In the modern poultry industry, chickens are subject to various stress factors that can thus influence lipid metabolism [22-24]. Studies show that the livers of broilers suffering from NE undergo pathological changes [4, 25, 26]; nonetheless, changes in the lipids of broilers infected with $C$. perfringens are rarely investigated. At present, few studies have demonstrated the efficacy of $B$. licheniformis as prophylactic agents against NE in broilers. Therefore, the objectives of our present study are to investigate the effect of $B$. licheniformis on growth performance, on lipid metabolism, and on the hepatic expression of lipogenic genes in broilers infected with NE.

\section{Results}

Effect of Bacillus licheniformis on the growth performance of broilers suffering from necrotic enteritis

The mean values of BWG, feed intake (FI), and feed conversion ratio (FCR) are shown in Table 1. FI did not vary across all of the groups throughout the experimental period; moreover, the $B$. licheniformis supplement group significantly increased BWG and improved FCR in the first two weeks $(P<0.05)$ in comparison with the unsupplemented groups. In the final two-week period of the trial, the BWG of the infected chickens in the NE experimental model group (PC) were significantly lower than those of the negative control group (NC) by $11.5 \%$ $(P<0.05)$. In the same period, FCR impaired by approximately 12.4 points because of the NE infection in the PC group compared with the negative control. The BWG of the infected chickens supplemented with $B$. licheniformis increased significantly over those of the PC group $(P<0.05)$. Moreover, the FCR of the $\mathrm{BL}$ group did not differ
Table 1 The effect of Bacillus licheniformis on the growth performance suffering from necrotic enteritis*

\begin{tabular}{lllllll}
\hline Parameter & NC & PC & FC & BL & SEM & $P$-value \\
\hline Days 1 to 14 & & & & & & \\
BWG (g) & $361.33^{\mathrm{b}}$ & $358.42^{\mathrm{b}}$ & $367.13^{\mathrm{b}}$ & $382.25^{\mathrm{a}}$ & 4.32 & 0.026 \\
FI (g) & 519.84 & 521.70 & 523.92 & 522.25 & 2.63 & 0.194 \\
FCR(g/g) & $1.44^{\mathrm{a}}$ & $1.46^{\mathrm{a}}$ & $1.43^{\mathrm{a}}$ & $1.37^{\mathrm{b}}$ & 0.02 & 0.049 \\
Days 14 to 28 & & & & & \\
BWG (g) & $718.87^{\mathrm{a}}$ & $636.3^{\mathrm{b}}$ & $689.33^{\mathrm{ab}}$ & $712.93^{\mathrm{a}}$ & 10.76 & 0.023 \\
FI (g) & 1159.82 & 1149.27 & 1160.83 & 1161.40 & 15.41 & 0.968 \\
FCR(g/g) & $1.61^{\mathrm{b}}$ & $1.81^{\mathrm{a}}$ & $1.68^{\mathrm{ab}}$ & $1.63^{\mathrm{b}}$ & 0.03 & 0.027 \\
Days 1 to 28 & & & & & & \\
BWG (g) & $1080.20^{\mathrm{a}}$ & $994.67^{\mathrm{b}}$ & $1056.67^{\mathrm{ab}}$ & $1095.27^{\mathrm{a}}$ & 13.15 & 0.032 \\
FI(g) & 1679.64 & 1670.90 & 1684.72 & 1683.65 & 15.58 & 0.991 \\
FCR(g/g) & $1.56^{\mathrm{b}}$ & $1.69^{\mathrm{a}}$ & $1.60^{\mathrm{ab}}$ & $1.56^{\mathrm{b}}$ & 0.02 & 0.034 \\
\hline
\end{tabular}

$N C$ negative control group, $P C$ necrotic enteritis experimental model group, $F C$ fishmeal and coccidiosis vaccine challenge group, $B L$ NE group supplied with feed containing $B$. licheniformis

* Data are means for 5 replicates of 12 broiler chickens presented with the means \pm SEM

${ }^{* a, b}$ Means in the same column with different lower case letter differ significantly $(P<0.05)$

significantly throughout the final two-week period, from that of the broilers in the NC group.

Effect of Bacillus licheniformis on the serum biochemical parameters of broilers infected with necrotic enteritis The serum lipid parameters are presented in Fig. 1. The serum levels of triglycerides (TG) and low-density lipoprotein cholesterol (LDL-C) were unaffected by NE infection $(P>0.05)$ in all groups. The NE-infected birds in the PC group exhibited high glucose (GLU) and total cholesterol (TC) levels $(P<0.05)$. The stricken birds in the BL group, which were co-treated with $B$. licheniformis at a dose of $1.0 \times 10^{6} \mathrm{CFU} / \mathrm{g}$, displayed a considerably lower serum GLU level $(P<0.05)$ and a significantly higher highdensity lipoprotein cholesterol (HDL-C) level than the PC group did $(P<0.05)$. The values of all of the serum lipid statuses of the birds fed with a diet supplement containing $30 \%$ fishmeal and a coccidiosis vaccine (FC group) did not differ significantly from those of NC group.

\section{Effect of Bacillus licheniformis on the serum antioxidant statuses of broilers suffering necrotic enteritis}

The serum antioxidant statuses of the broilers are presented in Fig. 2. Serum superoxide dismutase (SOD) activity did not vary significantly across all of the groups; furthermore, the malondialdehyde (MDA) content in the PC group that was infected with NE and was not supplemented with $B$. licheniformis was higher than that in the $\mathrm{NC}$ group, although the difference was insignificant.

Serum catalase (CAT) activity was significantly lower in the PC group that suffered from NE and was not 

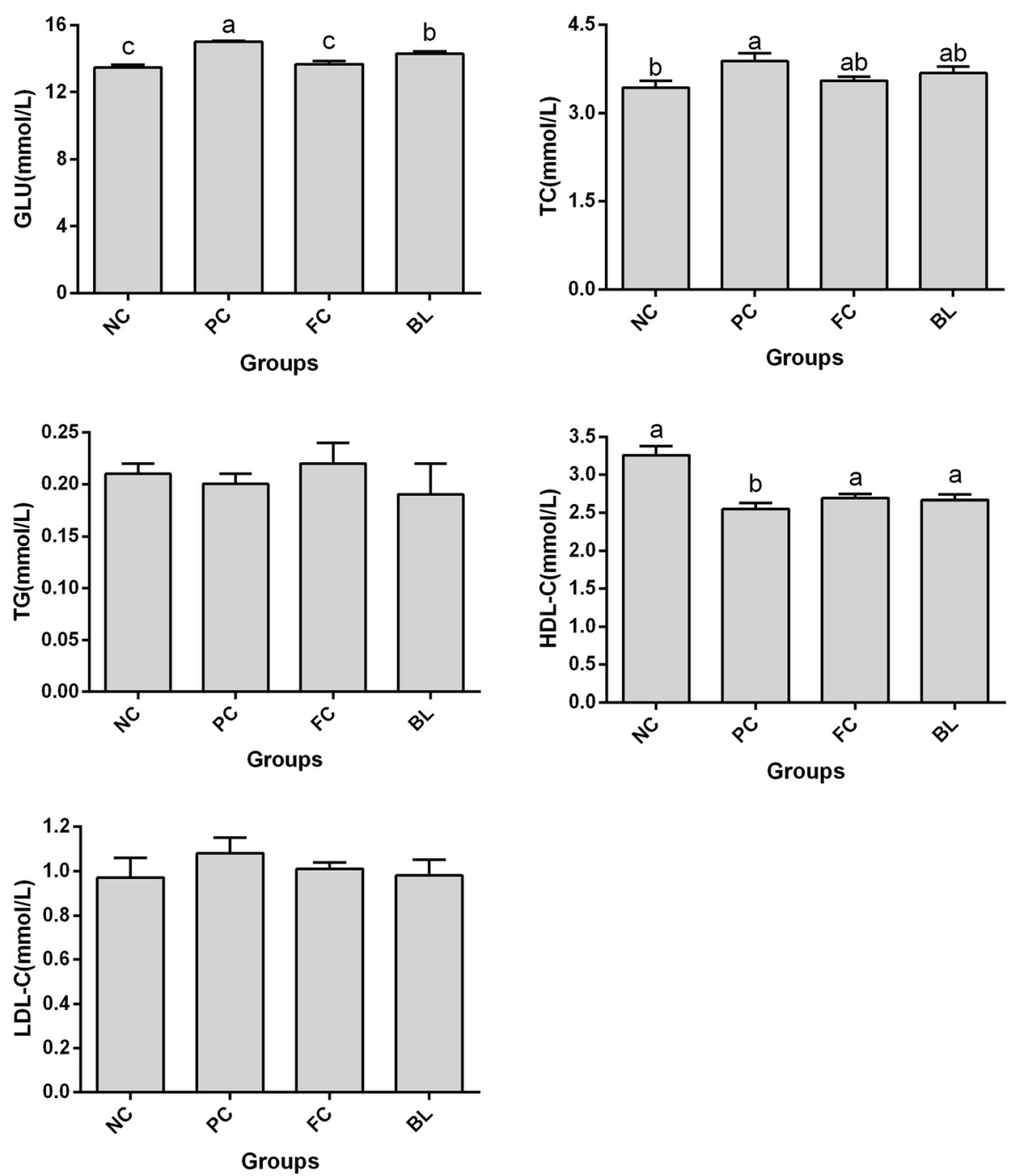

Fig. 1 The effect of Bacillus licheniformis on serum biochemical parameters of broilers infected with necrotic enteritis. NC: negative control group; PC: necrotic enteritis experimental model group; FC: fishmeal and coccidiosis vaccine challenge group, BL: NE group supplied with feed containing $B$. licheniformis. Data are with the means $\pm \operatorname{SEM}(n=10) .{ }^{\mathrm{a}-c}$ Means with different letter are significantly different $(P<0.05)$

supplemented with $B$. licheniformis than in the NC group $(P<0.05)$. The CAT activity of the chickens in the BL group displayed an increasing trend $(P>0.05)$ but did not differ from the NC and PC groups $(P>0.05)$.

$\mathrm{NE}$ infection considerably reduced the enzyme activity of glutathione peroxidase (GSH-Px) in both the PC and BL groups in comparison with the $\mathrm{NC}$ group $(P<0.05)$. The $\mathrm{NC}$ and FC groups did not vary significantly $(P>0.05)$.

Effect of Bacillus licheniformis on the expression of lipidmetabolism genes in the livers of broilers

As shown in Fig. 3, the mRNA level of acetyl-CoA carboxylase (ACC) in the livers of birds in the BL group, who were dosed with $1.0 \times 10^{6} \mathrm{CFU} / \mathrm{g} B$. licheniformis, was higher than those of the other three groups $(P<0.05)$. In addition, $B$. licheniformis did not significantly affect the expression of the fatty acid synthase (FAS) gene in the liver although the BL group displayed the highest expression $(P>0.05)$ of all of the groups. In addition, sterol regulatory element-binding protein-1c (SREBP-1c) expression was considerably lower in the BL group than in the $\mathrm{NC}$ and $\mathrm{PC}$ groups $(P<0.05)$.

B. licheniformis supplementation can upregulate the expression levels of genes related to fatty acid oxidation. This bacteria significantly increased the mRNA level of carnitine palmitoyltransferase-1 (CPT-1) and enhanced the expression of peroxisome proliferator-activated receptor- $\alpha$ (PPAR- $\alpha)$ in the BL group compared with the PC group $(P<0.05)$. Acyl CoA oxidase 1 (ACOX1) expression did not differ significantly across all groups $(P>0.05)$; nonetheless, that of the $\mathrm{BL}$ group was higher than that of the PC group. 

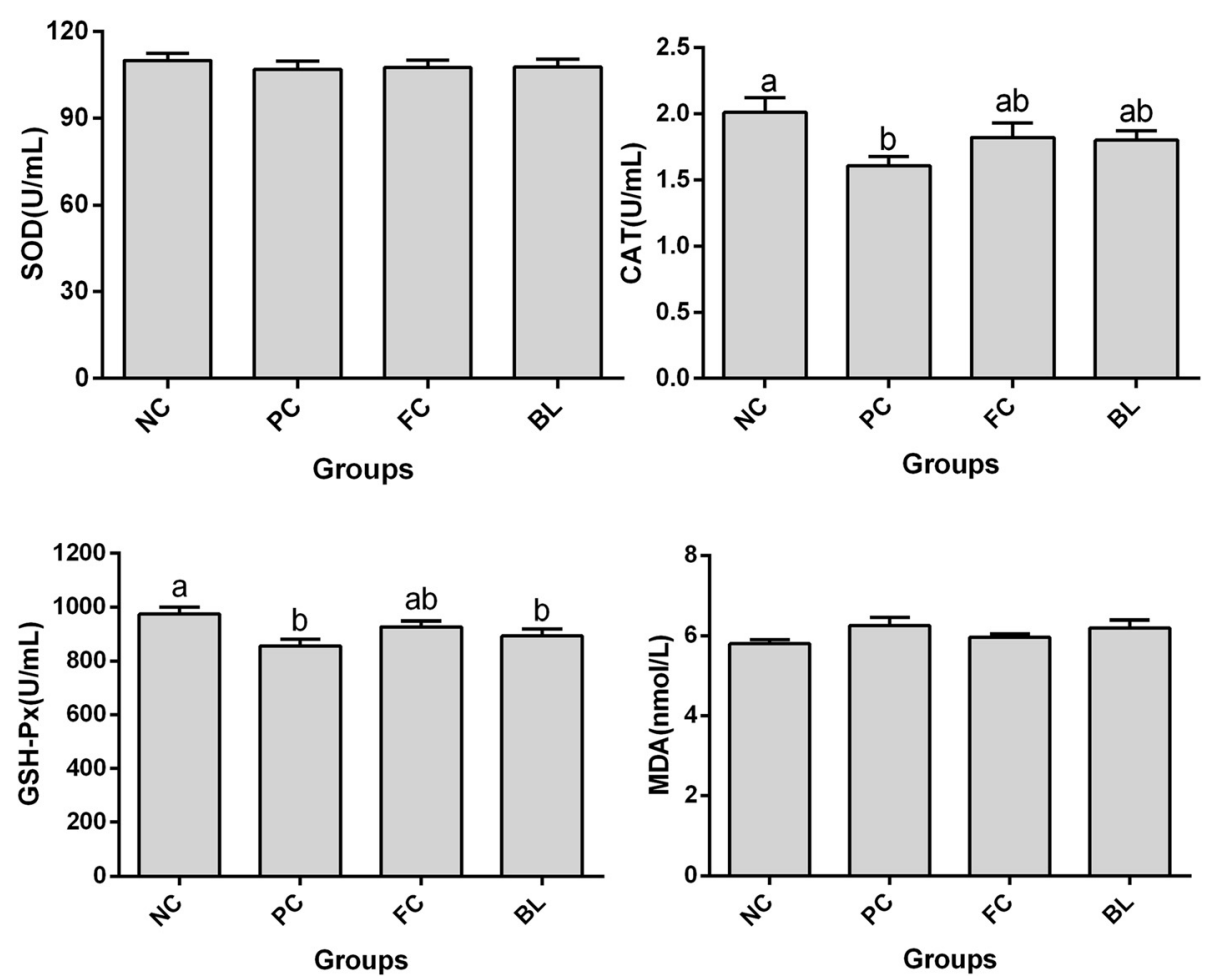

Fig. 2 The effect of Bacillus licheniformis on the serum antioxidant status of broilers suffering necrotic enteritis. NC: negative control group; PC: necrotic enteritis experimental model group; FC: fishmeal and coccidiosis vaccine challenge group, BL: NE group supplied with feed containing $B$. licheniformis. Data are means for 5 replicates of 12 broiler chickens presented with the means \pm SEM $(n=10)$. ${ }^{a} b$ Means with different letter are significantly different $(P<0.05)$

\section{Discussion}

In the present study, the growth performance of broilers infected with $C$. perfringens was significantly poorer in the PC group than in the other groups. The reduced BWG and impaired FCR can be indicated by the damaged intestinal mucosa that accompanies $C$. perfringens infection [27, 28], and this damage can affect feed absorption and thus utilization [18].

Bacillus sp. microbes are among the most extensively used, direct-fed growth promoters [15]. These bacteria serve as an alternative to antibiotics. In the current experiment, a diet supplemented with $B$. licheniformis can significantly improve BWG and FCR despite $C$. perfringens infection. These effects are mainly attributed to the fact that $B$. licheniformis can enhance nutrient digestion and utilization in broilers by producing several enzymes, such as lipase, protease, and amylase [29, 30]. The diets supplemented with Bacillus sp. as a growth promoter can improve BWG and feed efficiency [15, 24, 31, 32]. Nonetheless, the effects of $B$. licheniformis on positive responses to growth performance, such as changes in gut flora, immunity responses, and direct substrate digestion, remain unclear.

The level of fatty acid circulation between the liver and adipose tissue is related to the containment of serum lipids and lipoproteins [33]. Several studies observed that probiotics can significantly reduce these levels in broilers $[34,35]$. These results may be attributed to the ability of probiotics to bind cholesterol in guts; probiotics can remove cholesterol through binding onto cellular surfaces [36] and also can convert cholesterol to coprostanol for direct excretion via feces [37, 38]. Increased fecal-lipid and bile-acid output can reduce accumulate serum levels and liver lipids in the body [39].

The present data demonstrate that the birds infected with NE exhibited the highest level of GLU, TC, and LDL-C among those in all of the groups. NE-infected birds that were co-treated with $B$. licheniformis in this study had low concentrations of TC, GLU, and LDL-C but high levels of HDL-C. This result agrees with the finding presented by Yeon et al., who suggested that $B$. licheniformis can improve lipid metabolism in mice who were fed a high-fat diet [40].

Researchers hypothesize that oxidative stress influences growth performance and lipid metabolism in animals $[15,24,41,42]$. In the present study, SOD, CAT, and GSH-Px serum activities were assayed as indices for serum antioxidant capacity, whereas MDA content served as an indicator to determine serum lipid peroxidation 

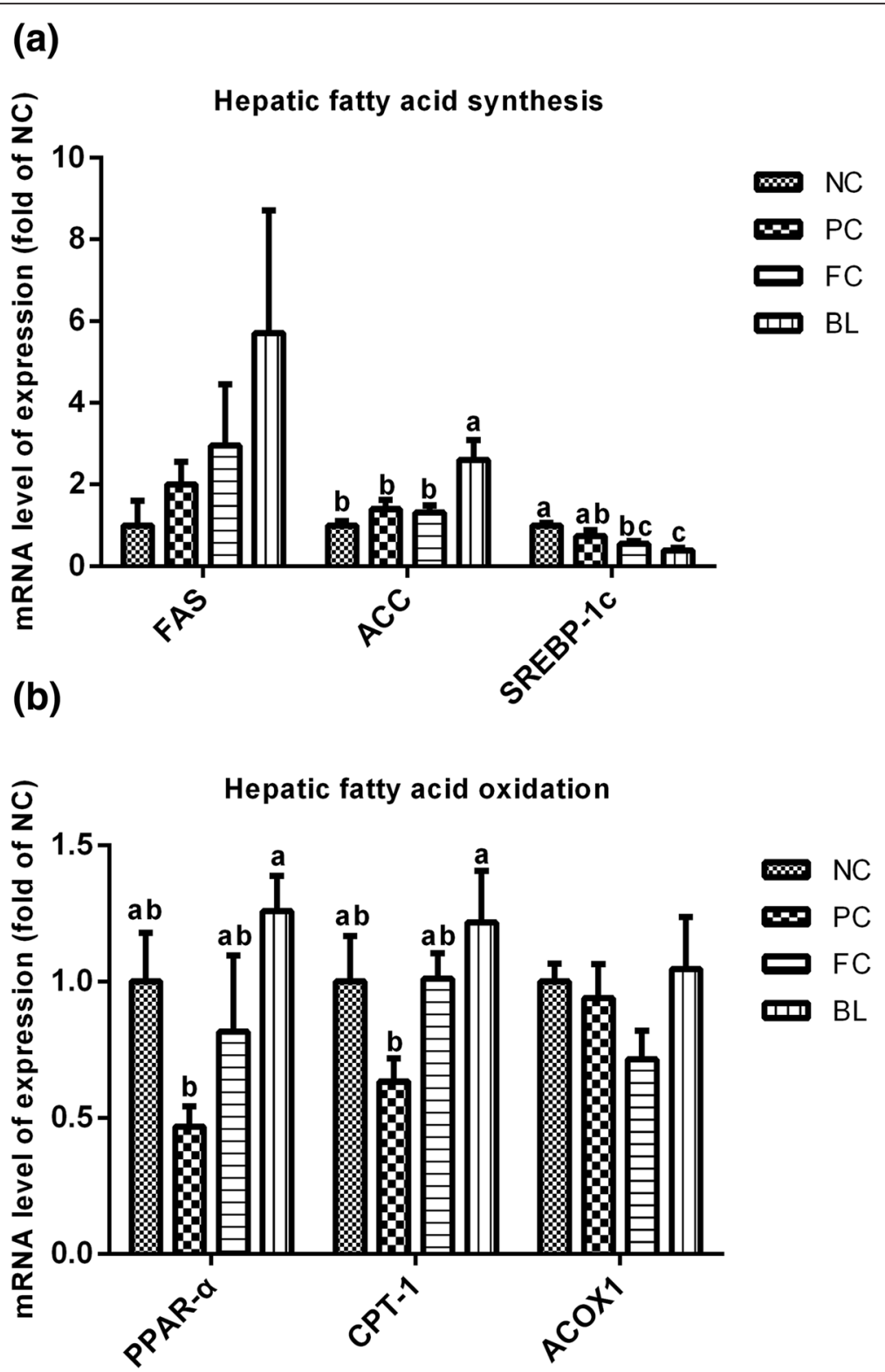

Fig. 3 Effect of Bacillus licheniformis on the expression of genes related to fatty acid synthesis (a) and oxidation (b) in the livers of broilers. NC: negative control group; PC: necrotic enteritis experimental model group; FC: fishmeal and coccidiosis vaccine challenge group, BL: NE group supplied with feed containing $B$. licheniformis. Data are the means \pm SEM of five chicks in each group. ${ }^{a-c}$ Means with different letters are significantly different $(P<0.05)$

levels. MDA is among the most studied products of polyunsaturated fatty acid peroxidation, and its lipid peroxidation is facilitated by reactive oxygen species (ROS). The BL group in the current study displayed a low MDA level, thus indicating that $B$. licheniformis treatment can reduce oxidative stress. The inhibition of SOD, GSH-Px, and CAT activities contributes to the onset of many diseases [43]. In the present study, NE infection lowered CAT and GSH-Px serum activities. This result is similar to that of the research conducted by Lee et al., which postulated that SOD, GSH-Px, and CAT activities were inhibited in birds infected with NE [44]. In a previous study, dietary $B$. licheniformis supplementation significantly enhanced the antioxidant capability of triangular breams [45]. In this research, BL group improved the antioxidant capacities in the serum of broilers by increasing GSH-Px and CAT activities and by decreasing MDA compared with the PC group. This result showed that dietary B. licheniformis supplementation is an effective strategy to reduce the oxidative stress of experimental avian NE.

The liver is an important organ in which the majority of lipid metabolism occurs. Thus, the gene expression in livers, which can change the capacity of enzymes in relevant metabolic pathways, plays an important role in 
altering digestive capability [19]. ACC, which is the first key enzyme in fatty acid synthesis and converts acetylCoA into malonyl-CoA, plays an important role in the regulation of fatty acid synthesis in animal tissues. This enzyme often combines with FAS as rate-limiting lipogenesis enzyme [46]. In the current study, both ACC and FAS levels increased in three of the groups, especially in the $\mathrm{BL}$ group, unlike in the NC group. This phenomenon may be ascribed to the diet change made to build the NE model. Huang et al. determined that diets supplemented with $0.5-2 \%$ soy lecithin can significantly increase the expression of FAS and ACC and change the biochemical status of serum lipids [47]. Zhao et al. reported that C. butyricum supplementation is related to increased FAS and ME activities, enhanced FAS, ME, and ACC mRNA levels in the liver, and increased intramuscular fat content in broilers [48]. In the current research, $B$. licheniformis supplementation can generate the same effect, possibly because $B$. licheniformis can enhance the digestion and utilization of nutrients from a diet containing a high percentage of fishmeal. This diet was used in the NE experimental model and was difficult for broilers to digest. SREBP-1c is a basic/helix-loophelix/leucine zipper transcription factor that contributes to lipogenic enzyme expression [49]. This transcription factor can bind to the promoters of several lipogenic enzyme genes and induce their expression [50]. Researchers also report that SREBP-1c is a lipogenic nuclear transcriptional regulator that can directly influence the expressions of ACC, FAS, ME, and SCD [51]. In our present study, however, SREBP-1c gene expression decreased significantly in contrast to the expression of lipogenic enzyme genes. This result may be attributed to the fact that fat composition is increasingly exuberant in the subsequent growth stage of broilers [52], especially as the diet changes and probiotics supplementation increases nutrient digestion and utilization in these chickens.

Different diets can alter the expression of PPARs in broiler livers [53]. PPAR- $\alpha$ plays an important role in lipid metabolism; an increase in the expression of this isoform can upregulate the expression of fatty acid catabolism-related genes (CPT-1, ACOX1) and enhance fatty acid $\beta$-oxidation $[54,55]$. In the present study, $B$. licheniformis can increase both PPAR- $\alpha$ and CPT- 1 expression. The expression of these genes was lowest in the NE-infected birds.

In summary, the present study shows that NE infection can change the expression of genes related to fatty acid synthesis and oxidation. B. licheniformis supplementation can adjust the levels of these genes by enhancing the expression of fatty acid $\beta$-oxidationrelated genes to alleviate the negative effects of such infection.

\section{Methods}

\section{Preparation of culture strains}

B. licheniformis H2 (CCTCC NO:M2011133) isolated from the ileums of healthy chickens was provided by the Animal Microecological Research Center (College of Veterinary Medicine, Sichuan Agricultural University, Chengdu, China) and cultured at $37{ }^{\circ} \mathrm{C}$ at a shaking rate of $180 \mathrm{rpm}$ for $24 \mathrm{~h}$. The culture was centrifuged at $2000 \mathrm{~g}$ for $20 \mathrm{~min}$ at $4{ }^{\circ} \mathrm{C}$ and then resuspended in LB broth containing $1 \times 10^{9}$ colony-forming units $(\mathrm{cfu}) / \mathrm{mL}$. The culture was mixed with a basal diet at a level of $1 \mathrm{~g} /$ $\mathrm{kg}(0.1 \%, \mathrm{~m} / \mathrm{m})$ per day to ensure the viability of bacteria cells throughout the trial period.

A C. perfringens type-A strain isolated from a chicken clinically diagnosed with NE was obtained from China Veterinary Culture Collection Center. The strain was cultured in a cooked meat medium at $37{ }^{\circ} \mathrm{C}$ under an anaerobic environment; then, the strain was aseptically inoculated into thioglycollate broth overnight at the same temperature and in the same condition.

\section{Birds and housing}

A total of 240 one-day-old broilers with similar body masses $(45.35 \pm 0.45 \mathrm{~g})$ were purchased from a local commercial hatchery. All of the broilers were randomly divided into four groups, with five replicates per treatment. Each replicate was assigned to a pen (12 chicks per pen). The four groups are as follows: (1) a negative control group fed with corn-soybean meal diet (NC, negative control); (2) an NE experimental model group (PC, positive control); (3) a group that was fed a diet supplemented with $30 \%$ of fishmeal from day 14 onwards and challenged with coccidiosis vaccine (FC, fishmeal and coccidia); and (4) an infected group given a diet supplemented with $B$. licheniformis $(\mathrm{BL}, B$. licheniformis at a dose of $\left.1.0 \times 10^{6} \mathrm{CFU} / \mathrm{g}\right)$. The composition of an un-medicated corn-soybean meal diet and high fishmeal diet is shown in Table 2. The diets were formulated according to NRC (1994) [56]. Feed and water were provided ad libitum throughout the study, and all chickens were fed in the same house under a relative humidity of approximately $65 \%$. The temperature was $33{ }^{\circ} \mathrm{C}$ in the first week and then decreased gradually to $24{ }^{\circ} \mathrm{C}$ by the third week. Lighting was provided $24 \mathrm{~h} /$ day. To prevent cross infection, the sides of the pens were composed of metal. Furthermore, the infected groups were kept at least $4 \mathrm{~m}$ away from the healthy groups. All experimental procedures were performed in compliance with the laws and guidelines of Sichuan Agricultural University Animal Care and Use Committee.

\section{Necrotic enteritis infection}

The birds were fed with a basal diet from days 1 to 13 . From day 14 onward, the diets of all of the birds were 
Table 2 Composition of the diet and nutrient levels

\begin{tabular}{|c|c|c|}
\hline Ingredient (g/kg) & $\begin{array}{l}\text { Corn-soybean meal } \\
\text { diet }\end{array}$ & $\begin{array}{l}\text { High fishmeal } \\
\text { diet }\end{array}$ \\
\hline Corn & 51.64 & 53.8 \\
\hline $\begin{array}{l}\text { Soybean ( } 44.2 \% \text { crude } \\
\text { protein) }\end{array}$ & 39.6 & 7.44 \\
\hline $\begin{array}{l}\text { Fish meal( } 62.8 \% \text { crude } \\
\text { protein) }\end{array}$ & 0.0 & 30.0 \\
\hline Colza oil & 4.3 & 4.3 \\
\hline Dicalcium phosphate & 1.85 & 1.85 \\
\hline Limestone & 1.3 & 1.3 \\
\hline D,L-Methionine & 0.2 & 0.2 \\
\hline Salt & 0.4 & 0.4 \\
\hline Choline & 0.18 & 0.18 \\
\hline Vitamin Premix ${ }^{a}$ & 0.03 & 0.03 \\
\hline Mineral Premix ${ }^{\mathrm{b}}$ & 0.5 & 0.5 \\
\hline \multicolumn{3}{|l|}{ Nutrient Level $^{c}$} \\
\hline Crude protein & 21.17 & 25.98 \\
\hline Metabolisable energy (MJ/kg) & 14.16 & 14.31 \\
\hline Methionine & 0.49 & 0.95 \\
\hline Lysine & 1.03 & 1.6 \\
\hline Threonine & 0.77 & 0.95 \\
\hline Calcium & 1.07 & 2.11 \\
\hline Total phosphorous & 0.71 & 1.35 \\
\hline
\end{tabular}

${ }^{a}$ Vitamin Premix provided the following per kilogram of complete feed: vitamin $\mathrm{A}, 50000 \mathrm{IU}$; vitamin $\mathrm{D}_{3}, 10000 \mathrm{IU}$; vitamin $\mathrm{E}$, $25 \mathrm{IU}$; vitamin $\mathrm{K}_{3}$, $35 \mathrm{mg}$; vitamin $B_{3}, 25 \mathrm{mg}$; vitamin $B_{2}, 16 \mathrm{mg}$; vitamin $B_{6}, 6 \mathrm{mg}$; vitamin $B_{1}$, $2 \mathrm{mg}$; vitamin $B_{12}, 0.03 \mathrm{mg}$; nicotinic, $25 \mathrm{mg}$; folic acid, $0.5 \mathrm{mg}$

${ }^{b}$ Mineral Premix provided the following per kilogram of basal diet: $\mathrm{Mn}$ (as manganese sulfate), $60.00 \mathrm{mg}$; Zinc (as zinc sulfate), $40.00 \mathrm{mg}$; Cu (as copper sulfate), $8.00 \mathrm{mg} ; \mathrm{Fe}$ (as ferrous sulfate), $80.00 \mathrm{mg} ; \mathrm{Se}$ (as sodium selenite), $0.15 \mathrm{mg}$; I (as potassium iodate), $0.35 \mathrm{mg}$

${ }^{c}$ Nutrient levels were calculated composition

changed to the basal diets supplemented with $30 \%$ fishmeal $(\mathrm{w} / \mathrm{w})$, except for that of the chickens in the $\mathrm{NC}$ group. On day 15, all of the birds, with the exception of those in the NC group, were inoculated with 10-fold coccidiosis vaccine by oral gavage. The birds in the NC group received sterile phosphate buffered saline instead. On days 18,19 , and 20 , the birds in the PC and $\mathrm{BL}$ groups were individually infected with $1 \mathrm{~mL}$ of $C$. perfringens through a plastic tube containing approximately $2.2 \times 10^{8} \mathrm{CFU} / \mathrm{mL}$ of this bacteria. The feed of the BL group was dosed with $1.0 \times 10^{6} \mathrm{CFU} / \mathrm{g}$ B. licheniformis throughout the experiment, and samples were collected on day 28.

On day 28, 2 birds per pen (10 birds/treatment) were randomly selected and terminated. The blood for the serum samples was sampled and incubated at $37{ }^{\circ} \mathrm{C}$ for $2 \mathrm{~h}$ and then centrifuged at $2000 \mathrm{~g}$ for $15 \mathrm{~min}$. The broilers were then killed by cervical dislocation and necropsied. The liver samples were washed with ice-cold sterilized saline and frozen in liquid nitrogen immediately.
The samples were then stored at $-70{ }^{\circ} \mathrm{C}$ to determine lipid metabolism mRNA.

\section{Growth performance}

The FI and BWG of the chickens in all pens were measured weekly. Moreover, FCR was calculated and adjusted for the dead broilers.

\section{Determination of serum biochemical values}

The serums TC, GLU, TG, HDL-C, and LDL-C were measured on day 28 with a GS200 automatic biochemical analyzer (Shenzhen Genius Electronics Co., Ltd., Shenzhen, China) according to the manufacturer's instructions.

\section{Determination of serum antioxidative status}

Activity of SOD, GSH-Px, and CAT activity, as well as the MDA content in serum, were assayed with commercially available assay kits (Nanjing Jiancheng Bioengineering Institute) in accordance with the manufacturer's instructions as indices for serum antioxidant capacities. In brief, the colorimetric method was used to measure CAT activity; SOD activity was calculated based on an auto-oxidant using the hydroxylamine method; GSH-Px activity was assayed according to a 5, 5'-dithiobis (2-nitrobenzoic acid) method; and MDA content was assayed via a thiobarbituric acid method and absorbance measurement at $532 \mathrm{~nm}$.

\section{Real-time quantitative polymerase chain reaction (RT- qPCR) analysis of gene expression}

The total RNA was extracted from liver samples with RNAiso Plus (TaKaRa, Dalian, China) according to the manufacturer's instructions. RNA quality was tested on $1.5 \%$ agarose gel by electrophoresis, and the quantity of RNA was determined by measuring the absorbance at 260 and $280 \mathrm{~nm}$ by using a spectrophotometer (Nanodrop 2000, Thermo Scientific, USA). A first-stand complementary DNA (cDNA) was reversed immediately with $1 \mu \mathrm{g}$ of total RNA using a Prime Script ${ }^{\mathrm{TM}} \mathrm{RT}$ reagent kit (TaKaRa, Dalian, China) according to the manufacturer's instructions. All cDNA were stored at $-70{ }^{\circ} \mathrm{C}$ for further use.

RT-qPCR analysis was conducted by using a CFX96 Real-Time PCR detection system (Bio-Rad, Hercules, CA, USA) with a SYBER Premix Ex Taq ${ }^{\mathrm{TM}}$ PCR kit (TaKaRa, Dalian, China). The thermocycler protocol was implemented at $95{ }^{\circ} \mathrm{C}$ for $5 \mathrm{~min}$, followed by 40 cycles with $15 \mathrm{~s}$ denaturation at $95{ }^{\circ} \mathrm{C}$ and $30 \mathrm{~s}$ annealing/extension at an optimized temperature. Finally, a melt curve analysis was conducted to verify the purity of the PCR products. The gene-related primers are listed in Table 3. In this procedure, glyceraldehyde-3-phosphate dehydrogenase (GADPH) was employed as a housekeeping gene to normalize the expression data. The 
Table 3 Primers used for real-time PCR

\begin{tabular}{|c|c|c|c|c|c|}
\hline Gene & Genbank number & Primers position & Primers sequnce (5' to $3^{\prime}$ ) & Annealing temperature $\left({ }^{\circ} \mathrm{C}\right)$ & References \\
\hline \multirow[t]{2}{*}{ ACC } & NM_205505 & Forward & AATGGCAGCTTTGGAGGTGT & 60.9 & [23] \\
\hline & & Reverse & TCTGTTTGGGTGGGAGGTG & & \\
\hline \multirow[t]{2}{*}{ FAS } & J03860 & Forward & CTATCGACACAGCCTGCTCCT & 62.0 & [23] \\
\hline & & Reverse & CAGAATGTTGACCCCTCCTACC & & \\
\hline \multirow[t]{2}{*}{ CPT-1 } & AY675193 & Forward & CAATGAGGTACTCCCTGAAA & 57.5 & {$[26]$} \\
\hline & & Reverse & CATTATTGGTCCACGCCCTC & & \\
\hline \multirow[t]{2}{*}{ PPAR- $a$} & AF163809 & Forward & TGGACGAATGCCAAGGTC & 60.3 & [26] \\
\hline & & Reverse & GATTTCCTGCAGTAAAGGGTG & & \\
\hline \multirow[t]{2}{*}{ SREBP-1C } & AY029224 & Forward & GAGGAAGGCCATCGAGTACA & 60.3 & {$[26]$} \\
\hline & & Reverse & GGAAGACAAAGGCACAGAGG & & \\
\hline \multirow[t]{2}{*}{ ACOX1 } & NM_001006205 & Forward & ATGTCACGTTCACCCCATCC & 54.0 & {$[21]$} \\
\hline & & Reverse & AGGTAGGAGACCATGCCAGT & & \\
\hline \multirow[t]{2}{*}{ GADPH } & NM_204305 & Forward & GGTGAAAGTCGGAGTCAACGG & 58.4 & {$[57]$} \\
\hline & & Reverse & CGATGAAGGGATCATTGATGGC & & \\
\hline
\end{tabular}

${ }^{a}$ ACC, acetyl-CoA carboxylase; FAS, fatty acid synthase; CPT-1, carnitine palmitoyl transferase 1; PPAR-a, peroxisome proliferator activated receptor-alpha; SREBP1c, sterol regulatory element binding protein 1; ACOX1, acyl CoA oxidase 1; GADPH, glyceraldehyde 3-phosphate dehydrogenase

$\Delta \Delta \mathrm{Ct}$ method was used to estimate mRNA abundance, and $\mathrm{Ct}$ is determined by $(\mathrm{Ct}$, target $-\mathrm{Ct}, \mathrm{GAPDH})$ treatment - (Ct, target - Ct, GAPDH) control. All of the samples $(n=5)$ in each group were analyzed in triplicate, and all gene expression results were presented as the fold difference between the NC and the treated groups.

\section{Statistical analysis}

Data were expressed as the mean \pm standard error of the mean (SEM). All of these data were analyzed with SPSS Version 20.0 for Windows (SPSS Inc., Chicago, Illinois, USA). A homogeneity test of variance was performed and the results analyzed with one-way analysis of variance. Specific treatments were compared via the least significant difference test at an assigned p-value of $<0.05$. Differences between the means were considered significant when $\mathrm{P}<0.05$.

\section{Conclusion}

The results of our present study showed that dietary $B$. licheniformis supplementation effectively alleviates the negative effects of NE infection. This supplement can also reduce antioxidant stress, enhance growth performance, and adjust the expression levels of certain key genes related to lipid metabolism. Furthermore, the study data may provide a new insight into the prevention and treatment of NE in broilers.

\section{Competing interest}

The authors declare that they have no competing interest.

\section{Authors' contributions}

M.Z., X.N. and D.Z. designed the experiments. M.Z., T.T. and B.J. performed the experiments. M.Z., Z.Y. and K.P. analyzed the experiment data. M.Z. wrote this paper. All authors read and approved the final manuscript.

\section{Acknowledgments}

This study was supported by the International Cooperative Project of Science and Technology Bureau of Sichuan Province (2013HH0055) and the Science and Technology Support Project of Science and Technology Bureau of Sichuan Province (2013NZ0042).

\section{Author details}

${ }^{1}$ Animal Microecology Institute, College of Veterinary Medicine, Sichuan Agricultural University, Chengdu, Sichuan, China. ${ }^{2}$ Key Laboratory of Animal Disease and Human Health of Sichuan Province, Chengdu, Sichuan, China. ${ }^{3}$ Animal Genetics and Breeding Institute, College of Animal Science and technology, Sichuan Agricultural University, Chengdu, Sichuan, China.

Received: 20 January 2016 Accepted: 2 March 2016

Published online: 08 March 2016

\section{References}

1. Songer JG, Meer RR. Genotyping of clostridium perfringensby polymerase chain reaction is a useful adjunct to diagnosis of clostridial enteric disease in animals. Anaerobe. 1996:2:197-203.

2. Immerseel FV, Buck JD, Pasmans F, Huyghebaert G, Haesebrouck F, Ducatelle R. Clostridium perfringens in poultry: an emerging threat for animal and public health. Avian Pathol. 2004;33:537-49.

3. McDevitt R, Brooker J, Acamovic T, Sparks N. Necrotic enteritis; a continuing challenge for the poultry industry. Worlds Poult Sci J. 2006;62:221-47.

4. Lovland A, Kaldhusdal M. Severely impaired production performance in broiler flocks with high incidence of Clostridium perfringens-associated hepatitis. Avian Pathol. 2001;30:73-81.

5. Van Immerseel F, Rood Jl, Moore RJ, Titball RW. Rethinking our understanding of the pathogenesis of necrotic enteritis in chickens. Trends Microbiol. 2009;17:32-6.

6. Collier C, Van Der Klis J, Deplancke B, Anderson D, Gaskins H. Effects of tylosin on bacterial mucolysis, Clostridium perfringens colonization, and intestinal barrier function in a chick model of necrotic enteritis. Antimicrob Agents Chemother. 2003;47:3311-7.

7. Knarreborg A, Simon MA, Engberg RM, Jensen BB, Tannock GW. Effects of dietary fat source and subtherapeutic levels of antibiotic on the bacterial community in the ileum of broiler chickens at various ages. Appl Environ Microbiol. 2002;68:5918-24.

8. Torok VA, Allison GE, Percy NJ, Ophel-Keller K, Hughes RJ. Influence of antimicrobial feed additives on broiler commensal posthatch gut microbiota development and performance. Appl Environ Microbiol. 2011;77:3380-90. 
9. Lee KW, Lillehoj $H$, Jeong W, Jeoung H-Y, An D-J. Avian necrotic enteritis: experimental models, host immunity, pathogenesis, risk factors, and vaccine development. Poult Sci. 2011;90:1381-90.

10. McReynolds J, Byrd J, Anderson R, Moore R, Edrington T, Genovese K, et al. Evaluation of immunosuppressants and dietary mechanisms in an experimental disease model for necrotic enteritis. Poult Sci. 2004;83:1948-52

11. Tactacan G, Schmidt J, Miille M, Jimenez D. A Bacillus subtilis (QST 713) spore-based probiotic for necrotic enteritis control in broiler chickens. J Appl Poult Res. 2013;22:825-31.

12. Jayaraman S, Thangavel G, Kurian H, Mani R, Mukkalil R, Chirakkal H. Bacillus subtilis PB6 improves intestinal health of broiler chickens challenged with Clostridium perfringens-induced necrotic enteritis. Poult Sci. 2013;92:370-4

13. La Ragione RM, Woodward MJ. Competitive exclusion by Bacillus subtilis spores of Salmonella enterica serotype Enteritidis and Clostridium perfringens in young chickens. Vet Microbiol. 2003;94:245-56

14. Teo AY-L, Tan H-M. Inhibition of Clostridium perfringens by a novel strain of Bacillus subtilis isolated from the gastrointestinal tracts of healthy chickens. Appl Environ Microbiol. 2005;71:4185-90.

15. Attia $Y$, Zeweil H, Alsaffar A, El-Shafy A. Effect of non-antibiotic feed additives as an alternative to flavomycin on productivity, meat quality and blood parameters in broilers. Arch Fur Geflugelkunde. 2011;75:40-8.

16. Liu X, Yan H, Lv L, Xu Q, Yin C, Zhang K, et al. Growth performance and meat quality of broiler chickens supplemented with Bacillus licheniformis in drinking water. Asian-Australasian J Anim Sci. 2012;25:682.

17. Knap I, Lund B, Kehlet A, Hofacre C, Mathis G. Bacillus licheniformis prevents necrotic enteritis in broiler chickens. Avian Dis. 2010;54:931-5.

18. Attia Y, Ellakany H, El-Hamid AA, Bovera F, Ghazaly S. Control of Salmonella enteritidis infection in male layer chickens by acetic acid and/or prebiotics, probiotics and antibiotics. Arch Geflügelk. 2012;76:239-45.

19. Theil PK, Lauridsen C. Interactions between dietary fatty acids and hepatic gene expression in livers of pigs during the weaning period. Livest Sci. 2007;108:26-9

20. Griffin HD, Windsor D. Adipose tissue lipogenesis and fat deposition in leaner broiler chickens. J Nutr. 1992;122:363.

21. Huang J, Zhang Y, Zhou Y, Zhang Z, Xie Z, Zhang J, et al. Green tea polyphenols alleviate obesity in broiler chickens through the regulation of lipid-metabolism-related genes and transcription factor expression. J Agric Food Chem. 2013;61:8565-72.

22. Saneyasu T, Shiragaki M, Nakanishi K, Kamisoyama H, Honda K. Effects of short term fasting on the expression of genes involved in lipid metabolism in chicks. Comp Biochem Physiol B Biochem Mol Biol. 2013; 165:114-8.

23. Cai $Y$, Song $Z$, Zhang $X$, Wang $X$, Jiao $H$, Lin $H$. Increased de novo lipogenesis in liver contributes to the augmented fat deposition in dexamethasone exposed broiler chickens (Gallus gallus domesticus). Comp Biochem Physiol C Toxicol Pharmacol. 2009;150:164-9.

24. Attia Y, Hassan R, Tag El-Din A, Abou-Shehema B. Effect of ascorbic acid or increasing metabolizable energy level with or without supplementation of some essential amino acids on productive and physiological traits of slowgrowing chicks exposed to chronic heat stress. J Anim Physiol Anim Nutr. 2011;95:744-55.

25. Løvland A, Kaldhusdal M. Liver lesions seen at slaughter as an indicator of necrotic enteritis in broiler flocks. FEMS Immunol Med Microbiol. 1999:24:345-51.

26. Yang X, Zhuang J, Rao K, Li X, Zhao R. Effect of early feed restriction on hepatic lipid metabolism and expression of lipogenic genes in broiler chickens. Res Vet Sci. 2010;89:438-44.

27. Dahiya J, Hoehler D, Van Kessel AG, Drew MD. Dietary encapsulated glycine influences Clostridium perfringens and Lactobacilli growth in the gastrointestinal tract of broiler chickens. J Nutr. 2007;137:1408-14

28. Liu D, Guo Y, Wang Z, Yuan J. Exogenous lysozyme influences Clostridium perfringens colonization and intestinal barrier function in broiler chickens. Avian Pathology. 2010;39:17-24.

29. Santoso U, Tanaka K, Ohtani S, Sakaida M. Effect of fermented product from Bacillus subtilis on feed conversion efficiency, lipid accumulation and ammonia production in broiler chicks. Asian-Australasian J Anim Sci. 2001;14:333-7.

30. Rozs M, Manczinger L, Vágvölgyi C, Kevei F. Secretion of a trypsin-like thiol protease by a new keratinolytic strain of Bacillus licheniformis. FEMS Microbiol Lett. 2001;205:221-4.
31. Lei K, Li Y, Yu D, Rajput I, Li W. Influence of dietary inclusion of Bacillus licheniformis on laying performance, egg quality, antioxidant enzyme activities, and intestinal barrier function of laying hens. Poult Sci. 2013;92:2389-95.

32. Xu C-L, Ji C, Ma Q, Hao K, Jin Z-Y, Li K. Effects of a dried Bacillus subtilis culture on egg quality. Poult Sci. 2006;85:364-8.

33. Mossab A, Lessire M, Guillaumin S, Kouba M, Mourot J, Peiniau P, et al. Effect of dietary fats on hepatic lipid metabolism in the growing turkey. Comp Biochem Physiol B Biochem Mol Biol. 2002;132:473-83.

34. Kalavathy R, Abdullah N, Jalaludin S, Ho Y. Effects of Lactobacillus cultures on growth performance, abdominal fat deposition, serum lipids and weight of organs of broiler chickens. Br Poult Sci. 2003;44:139-44.

35. Sohail M, ljaz A, Yousaf M, Ashraf K, Zaneb H, Aleem M, et al. Alleviation of cyclic heat stress in broilers by dietary supplementation of mannanoligosaccharide and Lactobacillus-based probiotic: Dynamics of cortisol, thyroid hormones, cholesterol, C-reactive protein, and humoral immunity. Poult Sci. 2010;89:1934-8.

36. Kimoto $\mathrm{H}$, Ohmomo S, Okamoto T. Cholesterol removal from media by lactococci. J Dairy Sci. 2002;85:3182-8.

37. Lye H-S, Rusul G, Liong M-T. Removal of cholesterol by lactobacilli via incorporation and conversion to coprostanol. J Dairy Sci. 2010;93:1383-92.

38. Chiang Y-R, Ismail W, Heintz D, Schaeffer C, Van Dorsselaer A, Fuchs G. Study of anoxic and oxic cholesterol metabolism by Sterolibacterium denitrificans. J Bacteriol. 2008:190:905-14.

39. Lin Y-L, Chang Y-Y, Yang D-J, Tzang B-S, Chen Y-C. Beneficial effects of noni (Morinda citrifolia L.) juice on livers of high-fat dietary hamsters. Food Chem. 2013;140:31-8.

40. Yeon S-J, Kim S-K, Kim JM, Lee S-K, Lee C-H. Effects of fermented pepper powder on body Fat accumulation in mice Fed a high-Fat diet. Biosci Biotechnol Biochem. 2013;77:2294-7.

41. Ming M, Guanhua L, Zhanhai Y, Guang C, Xuan Z. Effect of the Lycium barbarum polysaccharides administration on blood lipid metabolism and oxidative stress of mice fed high-fat diet in vivo. Food Chem. 2009:113:872-7.

42. Iqbal M, Pumford N, Tang Z, Lassiter K, Ojano-Dirain C, Wing T, et al. Compromised liver mitochondrial function and complex activity in low feed efficient broilers are associated with higher oxidative stress and differential protein expression. Poult Sci. 2005;84:933-41.

43. Baker JS, Bailey DM, Hullin D, Young I, Davies B. Metabolic implications of resistive force selection for oxidative stress and markers of muscle damage during 30 s of high-intensity exercise. Eur J Appl Physiol. 2004;92:321-7.

44. Lee $\mathrm{S}$, Lillehoj $\mathrm{H}$, Jang $\mathrm{S}$, Jeong $\mathrm{M}, \mathrm{Xu} \mathrm{S}, \mathrm{Kim} J$, et al. Effects of in ovo injection with selenium on immune and antioxidant responses during experimental necrotic enteritis in broiler chickens. Poult Sci. 2014;93:111321.

45. Zhang C-N, Li X-F, Xu W-N, Jiang G-Z, Lu K-L, Wang L-N, et al. Combined effects of dietary fructooligosaccharide and Bacillus licheniformis on innate immunity, antioxidant capability and disease resistance of triangular bream (Megalobrama terminalis). Fish Shellfish Immunol. 2013;35:1380-6.

46. Wang $X$, Tian W. Green tea epigallocatechin gallate: a natural inhibitor of fatty-acid synthase. Biochem Biophys Res Commun. 2001;288:1200-6.

47. Huang J, Yang D, Gao S, Wang T. Effects of soy-lecithin on lipid metabolism and hepatic expression of lipogenic genes in broiler chickens. Livest Sci. 2008;118:53-60

48. Zhao X, Guo Y, Guo S, Tan J. Effects of Clostridium butyricum and Enterococcus faecium on growth performance, lipid metabolism, and cecal microbiota of broiler chickens. Appl Microbiol Biotechnol. 2013:97:6477-88.

49. Osborne TF. Sterol regulatory element-binding proteins (SREBPs): key regulators of nutritional homeostasis and insulin action. J Biol Chem. 2000; 275:32379-82.

50. Tabor DE, Kim JB, Spiegelman BM, Edwards PA. Transcriptional activation of the stearoyl-CoA desaturase 2 gene by sterol regulatory element-binding protein/adipocyte determination and differentiation factor 1. J Biol Chem. 1998:273:22052-8

51. Richards MP, Poch SM, Coon CN, Rosebrough RW, Ashwell CM, McMurtry JP. Feed restriction significantly alters lipogenic gene expression in broiler breeder chickens. J Nutr. 2003;133:707-15.

52. Lin C, Friars G, Moran E. Genetic and environmental aspects of obesity in broilers. Worlds Poult Sci J. 1980;36:103-11.

53. Royan M, Meng GY, Othman F, Sazili AQ, Navidshad B. Effects of conjugated linoleic acid, fish oil and soybean oil on PPARs $(a \& \gamma)$ mRNA expression in broiler chickens and their relation to body fat deposits. Int J Mol Sci. 2011; 12:8581-95. 
54. Han S, Vaziri ND, Gollapudi P, Kwok V, Moradi H. Hepatic fatty acid and cholesterol metabolism in nephrotic syndrome. Am J Transl Res. 2013;5:246.

55. Torra IP, Gervois P, Staels B. Peroxisome proliterator-activated receptor alpha in metabolic disease, inflammation, atherosclerosis and aging. Curr Opin Lipidol. 1999;10:151-60.

56. NRC. Nutrient Requirements of Poultry. 9th ed. Washington: The National Academies Press; 1994.

57. Druyan S, Cahaner A, Ashwell C. The expression patterns of hypoxiainducing factor subunit a-1, heme oxygenase, hypoxia upregulated protein 1 , and cardiac troponin T during development of the chicken heart. Poult Sci. 2007:86:2384-9.

Submit your next manuscript to BioMed Central and we will help you at every step:

- We accept pre-submission inquiries

- Our selector tool helps you to find the most relevant journal

- We provide round the clock customer support

- Convenient online submission

- Thorough peer review

- Inclusion in PubMed and all major indexing services

- Maximum visibility for your research

Submit your manuscript at www.biomedcentral.com/submit
Biomed Central 